\title{
Intracellular Polysaccharide of Bacteroides fragilis
}

\author{
By J. G. E. M. LINDNER, J. H. MARCELIS, N. M. DE VOS \\ AND J. A. A. HOOGKAMP-KORSTANJE \\ Anaerobe Section of the Laboratory of Microbiology, State University, \\ Catharijnesingel 59, Utrecht, The Netherlands
}

(Received 16 June 1978)

\begin{abstract}
Formation of iodophilic polysaccharide (IPS) from glucose was demonstrated in 27 strains of Bacteroides fragilis. Synthesis was dependent on the glucoseconcentration of the medium, the $\mathrm{pH}$ and the growth phase. When glucose was in short supply the cellular polysaccharide was degraded rapidly at $\mathrm{pH} 4.5$ to 6.5 and fatty acids accumulated in the medium. Storage of IPS was not responsible for the low carbon recoveries observed in fermentation balance studies. In electron micrographs of thin sections, the IPS was observed as cytoplasmic granules dispersed throughout the whole cell. After extraction and purification the IPS was characterized as a glycogen.
\end{abstract}

\section{INTRODUCTION}

Gas chromatographic analysis of fatty acids has greatly facilitated the identification and classification of the genus Bacteroides. In saccharolytic strains, the main products are succinic, acetic, lactic and propionic acids. Quantitative gas chromatography permits detailed studies of fermentation balances. In our studies of these balances in growing cultures of $B$. fragilis strains, we found that $\mathrm{C}$ recoveries ranged from 73 to $100 \%$, whereas residual glucose could never be demonstrated. The low $\mathrm{C}$ recovery might be explained by the formation of some other products, not detected by gas chromatographic analysis, or by the synthesis of polysaccharides from glucose. The latter process is well known in streptococci (Crowley \& Jevons, 1955; Gibbons \& Socransky, 1962), diphtheroids (Gibbons \& Socransky, 1962) and fusobacteria (Gibbons \& Socransky, 1962; Van Houte, 1967).

In the present work, we have studied the synthesis of iodophilic polysaccharide (IPS) by $B$. fragilis, the localization of the IPS and its nature and physical properties.

\section{METHODS}

Organisms. Bacteroides fragilis NCTC 9343, 9344, 10583, B. fragilis subsp. thetaiotaomicron NCTC 10582 and 23 strains of $B$. fragilis isolated from stool or pus [subsp. fragilis ( 9 strains), subsp. distasonis (7), subsp. vulgatus (5), subsp. ovatus (1) and subsp. thetaiotaomicron (1)] were used. All strains were identified by the procedures outlined by Holdeman \& Moore (1972); gas chromatographic analysis of fatty acids was performed according to Lindner \& Marcelis (1978). All strains were tested for IPS production.

Cultural methods. Viande-Levure medium (Beerens \& Fievez, 1971) with $2 \mathrm{mg}$ haemin $1^{-1}$ (HVL) and synthetic medium (SM) according to Macy et al. (1975) were used as basal media. HVL medium with $1.5 \%(\mathrm{w} / \mathrm{v})$ Difco Bacto-agar was used as a solid medium. All media were used freshly poured. The cultures were incubated anaerobically in jars under an atmosphere of $\mathrm{H}_{2} / \mathrm{CO}_{2}(9: 1, \mathrm{v} / \mathrm{v})$.

Growth was assayed in terms of the absorbance at $660 \mathrm{~nm}\left(A_{680}\right)$ measured using a Klett-Summerson photoelectric colorimeter (filter no. 66).

Dry weight was determined by filtration according to Stouthamer (1969). The membrane filters used (Sartorius, Göttingen, West Germany) had a pore size of $0.2 \mu \mathrm{m}$.

Determination of fermentation balances. At various times during growth, $10 \mathrm{ml}$ samples were taken from a culture in HVL with $27 \mathrm{~mm}$-glucose, and centrifuged. Fatty acids in the supernatant solution were 
determined quantitatively by gas chromatography. The residual glucose was determined enzymically according to Huggett \& Nixon (1957) by means of a test combination containing glucose oxidase and peroxidase (Boehringer) or with hexokinase (Schmidt, 1961). Carbon recoveries were calculated according to Dawes et al. (1971). No gas production was observed.

Determination of IPS. Bacteria from $10 \mathrm{ml}$ samples of cultures grown in HVL for 24 to $36 \mathrm{~h}$ were washed once with saline $[0.85 \%(\mathrm{w} / \mathrm{v}) \mathrm{NaCl}]$ and resuspended in saline to an $A_{660}$ of 80 to 100 Klett units. To $10 \mathrm{ml}$ of this suspension $2 \mathrm{ml}$ of a solution of $0.2 \%(\mathrm{w} / \mathrm{v}) \mathrm{I}_{2}$ in $2 \%(\mathrm{w} / \mathrm{v}) \mathrm{KI}$ was added (Van Houte, 1967). The absorbance of the IPS-iodine complex $\left(E_{1}\right)$ was measured at $540 \mathrm{~nm}$ (filter no. 54); the absorbance of the same suspension without iodine was used as a blank $\left(E_{0}\right)$. The photoelectric colorimeter was adjusted with $10 \mathrm{ml}$ water and $2 \mathrm{ml}$ iodine solution. The amount of IPS was expressed as Brown Value (BV) = $\left[\left(E_{1}-E_{0}\right) / E_{0}\right] \times 100$.

Preparation of cell suspensions. Bacteria from a $250 \mathrm{ml}$ culture in SM with $14 \mathrm{~mm}$-glucose incubated for $24 \mathrm{~h}$ at $37^{\circ} \mathrm{C}$ were harvested by centrifuging $(1000 \mathrm{~g}, 30 \mathrm{~min})$, washed twice in sterile saline and resuspended in $30 \mathrm{ml}$ saline.

Determination of the effect of $p H$ on IPS content. Portions $(1 \mathrm{ml})$ of cell suspension were added in triplicate to tubes containing $5 \mathrm{ml} 0.06 \mathrm{M}$-Sørensen phosphate buffer ( $\mathrm{pH}$ range 4 to 8 ) supplemented with $14 \mathrm{mM}$ glucose. After 3, 6, 20 or $48 \mathrm{~h}$ at $37^{\circ} \mathrm{C}$, the $\mathrm{pH}$, residual glucose and the amount of IPS were measured.

Preparation of cell-free extracts. Bacteria were frozen and passed through a French press according to Hughes et al. (1971). Disrupted material was centrifuged for $30 \mathrm{~min}$ at $36000 \mathrm{~g}$. The IPS contents of both the wall fraction and the supernatant solution were determined.

Isolation and purification of IPS. The cell-free extract obtained from bacteria grown in $3.61 \mathrm{SM}$ with $56 \mathrm{~mm}$-glucose was incubated with $1 \mathrm{mg}$ lysozyme $\mathrm{ml}^{-1}$ (Fluka, Germany) at $37^{\circ} \mathrm{C}$ for $1 \mathrm{~h}$ to remove contaminating wall residues. Subsequent extraction followed the procedures of Gibbons \& Kapsimalis (1963). The polysaccharide was dialysed against water at $4{ }^{\circ} \mathrm{C}$ for $4 \mathrm{~d}$ and lyophilized.

Analytical methods. The reaction of iodine with polysaccharide was studied by adding $1 \mathrm{ml}$ of the iodine solution to $5 \mathrm{ml}$ of a solution containing $1 \mathrm{mg}$ polysaccharide. The absorbance of the iodine-polysaccharide complex was monitored between 250 and $750 \mathrm{~nm}$ using a Perkin Elmer 124 spectrophotometer. Water and the same iodine solution were used as blanks.

Standard curves were prepared relating the concentration of iodine-polysaccharide complexes to absorbance at $540 \mathrm{~nm}$ measured using a Klett-Summerson photoelectric colorimeter (filter no. 54).

The optical rotation of a solution containing $26.5 \mathrm{mg}$ polysaccharide in $10 \mathrm{ml} 1 \mathrm{M}-\mathrm{NaOH}$ was measured on a Bendix Ericsson Automatic Polarimeter type 143A using the sodium D line at $589 \mathrm{~nm}$.

The molecular weight of the polysaccharide was determined using a $10 \mathrm{ml}$ Sephadex 4B column and $0.85 \%(\mathrm{w} / \mathrm{v}) \mathrm{NaCl}$ as eluant. Fractions of $0.45 \mathrm{ml}$ were collected and tested for neutral sugars by the phenol/ $/ \mathrm{H}_{2} \mathrm{SO}_{4}$ method (Dubois et al., 1956) and for iodine-staining power. Molecular weight standards were from the following sources: apotransferrin (Boehringer), polyvinylpyrrolidone-DNP ${ }_{35}$ (kindly supplied by Dr H. Snippe, Department of Immunology, Laboratory of Microbiology, Utrecht, The Netherlands), rabbit liver glycogen (Boehringer), dextran HM VII (Poviet Production, Amsterdam, The Netherlands), blue dextran 2000 (Pharmacia).

Acid hydrolysis of polysaccharide. Samples were hydrolysed with $1 \mathrm{M}-\mathrm{HCl}$ at $100^{\circ} \mathrm{C}$ for 0.5 to $8 \mathrm{~h}$. The $\mathrm{HCl}$ was neutralized with $2 \mathrm{M}-\mathrm{NaOH}$.

Enzymic hydrolysis of polysaccharide. For hydrolysis of 1,4- $\alpha$ and 1,6- $\alpha$ bonds, samples were treated with amyloglucosidase. For hydrolysis of $1,4-\alpha$ bonds, samples were treated with $\beta$-amylase followed by maltase to degrade disaccharides. The glucose contents of the digests were determined by means of a Biochemica test combination (hexokinase method). Enzymes were obtained from Boehringer.

For detection of carbohydrates, thin-layer chromatography of hydrolysates and digests was carried out according to Lato et al. (1969). Chromatographic standards were: D-glucose, D-fructose, D-rhamnose, maltose, glyceraldehyde and rabbit liver glycogen. Amino acids were detected by ninhydrin $(1 \%, \mathrm{w} / \mathrm{v}$, in acetone).

Electron microscopy. Cells cultivated in SM with $56 \mathrm{mM}$-glucose $\left(24 \mathrm{~h}\right.$ at $\left.37^{\circ} \mathrm{C}\right)$ or $14 \mathrm{mM}$-glucose $(48 \mathrm{~h}$ at $37^{\circ} \mathrm{C}$ ) were centrifuged at $1000 \mathrm{~g}$ for $10 \mathrm{~min}$. The pellets were fixed in a solution containing $1 \%(\mathrm{w} / \mathrm{v})$ glutaraldehyde, $1 \%(\mathrm{w} / \mathrm{v})$ formaldehyde and $1 \%(\mathrm{w} / \mathrm{v})$ sucrose in $0 \cdot 1 \mathrm{M}$-phosphate buffer, $\mathrm{pH} 7 \cdot 4$, at room temperature for $45 \mathrm{~min}$. This was followed by postfixation in Palade-buffered $1 \%(\mathrm{w} / \mathrm{v}) \mathrm{OsO}_{4}$,

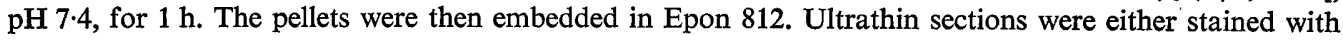
lead citrate for morphological examination or treated with periodic acid, thiocarbohydrazide and silver proteinate for the demonstration of polysaccharides according to Thiéry (1967). As a control for the latter method, periodic acid oxidation was omitted. Sections were examined in a Philips 301 electron microscope. 
Table 1. Fermentation balances in a growing culture of $B$. fragilis subsp. fragilis $\mathrm{C}_{161}$ in $S M$ with 28 mM-glucose

Time of incubation Dry weight

(h) $\quad\left(\mathrm{mg} \mathrm{1}^{-1}\right)$

$12 \quad 340$

$\begin{array}{ll}125 & 340 \\ 50 & 530\end{array}$

$50 \quad 530$

70
Fatty acids (mM)
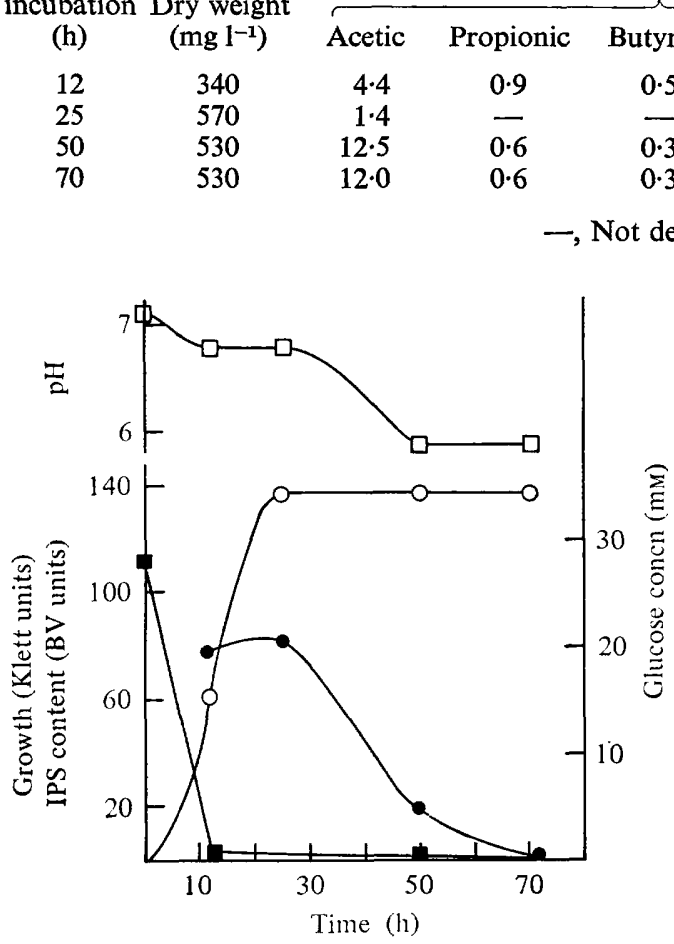

Fig. 1

$\begin{array}{cc}\begin{array}{c}\text { Residual } \\ \text { glucose } \\ \text { (mM) }\end{array} & \begin{array}{c}\text { C } \\ \text { recovery } \\ (\%)\end{array} \\ 1 \cdot 1 & 32 \\ 0.2 & 35 \\ 0.06 & 82 \\ 0.06 & 88\end{array}$

-, Not detectable.

$\begin{array}{ccc}\text { utyric } & \text { Lactic } & \text { Succinic } \\ 0 \cdot 5 & 2 & 5 \\ - & - & 10 \\ 0 \cdot 3 & 8 & 17 \\ 0.3 & 10 & 19\end{array}$

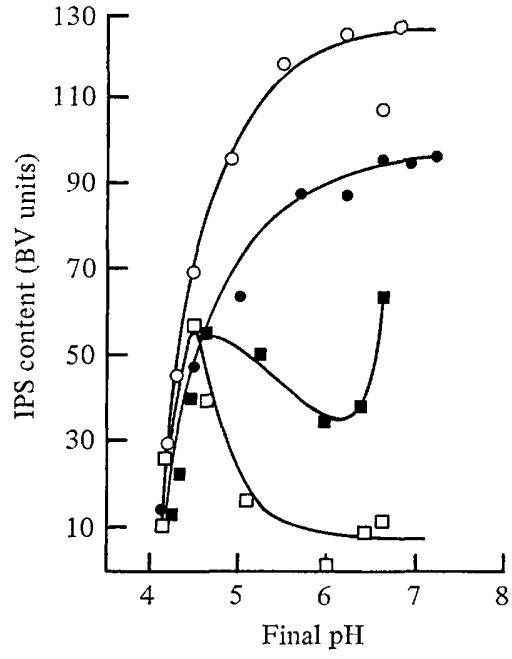

Fig. 2

Fig. 1. Growth of $B$. fragilis subsp. fragilis $\mathrm{C}_{161}$ expressed as Klett units of absorbance (O) and the corresponding values of IPS content of the cells in BV units (๑), pH ( $\square$ ) and glucose concentration (II) in the medium.

Fig. 2. The IPS content of cell suspensions of $B$. fragilis subsp. fragilis $\mathrm{C}_{\mathbf{1 6 1}}$ as a function of the

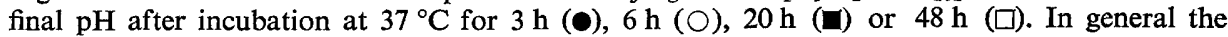
final $\mathrm{pH}$ was 0.5 lower than the initial $\mathrm{pH}$. The shape of the $20 \mathrm{~h}$ curve was confirmed in other experiments. No IPS could be detected at time zero.

\section{RESULTS}

IPS production was demonstrated in all strains of $B$. fragilis examined, the Brown Values (BV) varying from 15 to 150 . The observed BV was dependent on the phase of growth (Fig. 1). IPS synthesis started during the exponential phase and continued until the maximum growth yield was reached after $30 \mathrm{~h}$. In the first $20 \mathrm{~h}$ of the stationary phase the amount of IPS decreased to $25 \%$ of the maximum present at the end of the exponential phase; in the next $20 \mathrm{~h}$ it was totally consumed.

The glucose concentration decreased to $1 \cdot 1 \mathrm{~mm}$ after $10 \mathrm{~h}$. After $25 \mathrm{~h}$ growth, residual glucose could no longer be detected; the amount of fatty acids produced then increased sharply (Table 1) and at the same time the $\mathrm{pH}$ fell to $5 \cdot 9$.

Fermentation balances, calculated at different stages of growth of strain $\mathrm{C}_{161}$, are shown in Table 1. After $25 \mathrm{~h}$ growth, the dry weight value was high but the $\mathrm{C}$ recovery was low $(35 \%)$. After $70 \mathrm{~h}$ growth, the dry weight was similar but the $\mathrm{C}$ recovery was more satisfactory $\left(88 \%\right.$ ). Analogous experiments resulted in $\mathrm{C}$ recoveries of $98 \%$ for strain $\mathbf{B B}_{49}$ and $100 \%$ for $F_{24}$. 


\section{Influence of $p H$ on IPS synthesis and degradation}

The effect of $\mathrm{pH}$ on cellular polysaccharide content was studied using cell suspensions incubated in phosphate buffer, $\mathrm{pH} 4.5$ to 8 , with $14 \mathrm{mM}$-glucose (Fig. 2). At $\mathrm{pH} 4$ to 4.5 , IPS was synthesized in small quantities (BV 50) and was not degraded. The supernatant solution contained residual glucose. At $\mathrm{pH}$ values between 4.5 and 6.5 , IPS was rapidly synthesized in the first $6 \mathrm{~h}$ of incubation, up to BV 130. After $6 \mathrm{~h}$ no residual glucose could be detected. By $20 \mathrm{~h}$, degradation became apparent and the polysaccharide content was lower, and had fallen further by $48 \mathrm{~h}$. The rate of IPS production and degradation increased with the $\mathrm{pH}$. At higher $\mathrm{pH}(\geqslant 7)$ the synthesis was rapid up to $\mathrm{BV} 130$, but degradation was delayed. However, after $48 \mathrm{~h}$ IPS degradation was complete.

\section{Influence of glucose concentration on IPS synthesis}

The amount of IPS production in cell suspensions was directly correlated with the glucose concentration of the medium. At concentrations below $1.7 \mathrm{mM}$ no IPS was synthesized. At higher concentrations the rate of IPS synthesis increased reaching a maximum with $5.5 \mathrm{~mm}$-glucose in the medium.

\section{Localization of the IPS}

After disruption of bacteria, IPS was found in the cytoplasmic fraction but not in the wall fraction. The intracellular localization of IPS was confirmed by electron microscopy. In thin sections of cells having a high IPS content (BV 140), a regular dispersion of many electron-dense polysaccharide particles distributed over the whole bacterial cell was seen (Fig. $3 a, b$ ). In starved cells without IPS (BV 0), only a few particles of polysaccharide were apparent (Fig. 3c,d).

\section{Nature of the IPS}

The 3.61 culture incubated for $48 \mathrm{~h}$ at $37^{\circ} \mathrm{C}$ yielded $230 \mathrm{mg}$ purified and lyophilized polysaccharide.

The absorbance of the iodine-polysaccharide complex showed a maximum at $490 \mathrm{~nm}$. Commercial rabbit liver glycogen produced a brown colour with an absorption maximum at $495 \mathrm{~nm}$ when treated in the same manner. The iodine-staining power of the commercial glycogen was about twice that of the IPS, as calculated from the standard curves relating IPS and commercial glycogen concentration to absorbance.

Development of thin-layer chromatograms of the acid hydrolysates and enzymic digests of the IPS revealed a single compound with an $R_{F}$ value $(0 \cdot 15)$ equal to that of glucose. No peptide bonds or free amino acids could be detected, as no absorbance occurred at 250 to $280 \mathrm{~nm}$ and ninhydrin reactions were negative.

The calculated mol. wt was $304000 \pm 21000$ and the optical rotation of the IPS was $+167 \cdot 7^{\circ}$.

\section{DISCUSSION}

IPS synthesis by anaerobic bacteria was demonstrated in fusobacteria and leptotrichia isolated from dental plaque (Van Houte, 1967). This study shows that IPS synthesis from glucose or other carbohydrates is also a common characteristic of $B$. fragilis. The $B$. fragilis strains could rapidly catabolize the accumulated IPS if the carbohydrate in the medium was limited. The time interval between the disappearance of glucose and the decrease in $\mathrm{pH}$ or the formation of fatty acids suggests that the main formation of these acids is not due to fermentation of the initial glucose but to conversion of stored IPS. However, the low $\mathrm{C}$ recovery after $24 \mathrm{~h}$ growth cannot be explained in terms of the storage of IPS as the dry weight reached at that time would contribute to the $\mathrm{C}$ recovery the equivalent of only 12 to $13 \%$. Formation of intermediates not detected by gas chromatography or 

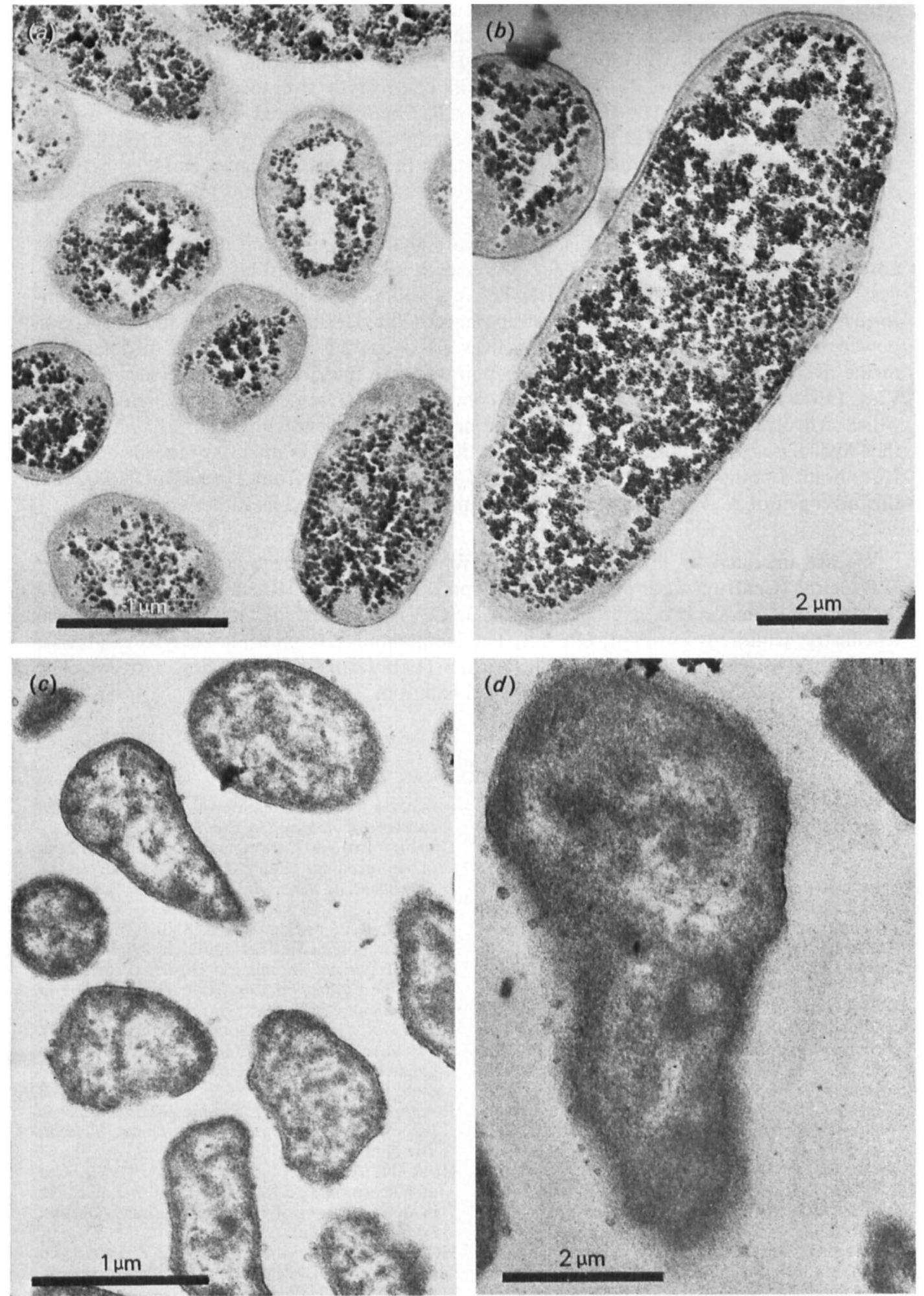

Fig. 3. Electron micrographs of B. fragilis subsp. fragilis $\mathrm{BB}_{2}:(a, b)$ cells containing IPS (BV 140) showing dispersed granules of electron-dense material; $(c, d)$ cells without IPS (BV 0). 
synthesis of extracellular products serving as substrates may be the cause of the deficiencies in the fermentation balances after $25 \mathrm{~h}$ growth.

Degradation of IPS was dependent on $\mathrm{pH}$ in the same manner as demonstrated in streptococci (Van Houte, 1967). However, in contrast to streptococci, no degradation occurred below $\mathrm{pH} 4 \cdot 5$. The IPS produced by $B$. fragilis is located intracellularly, as it is in streptococci (Gibbons \& Kapsimalis, 1963). In electron micrographs, the IPS of $B$. fragilis was observed as cytoplasmic granules, as in $E$. coli (Cedergren \& Holme, 1959), Streptococcus mutans (DiPersio et al., 1974) and Nocardia asteroides (DiPersio \& Deal, 1974).

The chemical properties of this IPS indicate that it is a glycogen. The similarity in absorbance, with a $\lambda_{\max }$ at $490 \mathrm{~nm}$ for IPS and at $495 \mathrm{~nm}$ for rabbit liver glycogen, suggests IPS may have a similar structure. The $\lambda_{\max }$ value of the glycogen of $B$. fragilis conforms to that of the glycogen from streptococci (Van Houte, 1967). The iodine-staining power of IPS differs from that of rabbit liver glycogen; this may be related to differences in the average distances between branch points in the interior of the molecules (Van de Vies, 1954). Digestion of the polymer was complete after treatment with amyloglucosidase, which hydrolyses $1,4-\alpha$ and 1,6- $\alpha$ bonds, but not after treatment with $\beta$-amylase, an enzyme that hydrolyses $1,4-\alpha$ bonds. This indicates that the polymer is an 1,4- $\alpha$-glucan joined by $1,6-\alpha$ branch points. As molecular weights of glycogens range from 270000 to 100000000 , this glycogen of $B$. fragilis (mol. wt 304000) must be considered as rather small.

We are indebted to Professor Dr K. C. Winkler for constructive discussions; to Dr J. J. Geuze (Centrum voor Medische Electronenmicroscopie, Utrecht, The Netherlands) for preparing the electron micrographs; to Dr C. van der Heiden (Department of Clinical Chemistry, Childrens Hospital, Utrecht, The Netherlands) for enzymic analysis of glucose and helpful discussion; and to Dr J. Renema (Laboratory of Pharmacy, Utrecht, The Netherlands) for the determination of optical rotation.

\section{REFERENCES}

BeERens, H. \& Fievez, L. (1971). Isolation of Bacteroides fragilis and Sphaerophorus fusiformis groups. Annales de l'Institut Pasteur 121, 109113.

Cedergren, B. \& Holme, T. (1959). On the glycogen of $E$. coli B. Electron microscopy of ultrathin sections of cells. Journal of Ultrastructural Research 3, 70-73.

Crowley, N. \& Jevons, M. P. (1955). The formation of a starch-like polysaccharide from maltose by strains of Streptococcus pyogenes. Journal of General Microbiology 13, 226-234.

Dawes, E. A., McGill, D. J. \& Midgley, M. (1971). Analysis of fermentation products. Methods in Microbiology 6A, 53-215.

DiPersio, J. R. \& DeAL, S. J. (1974). Identification of intracellular polysaccharide granules in thin sections of Nocardia asteroides. Journal of General Microbiology 83, 349-358.

DiPersio, J. R., Mattingly, S. J., Higgins, M. L. \& Shockmann, G. D. (1974). Measurement of intracellular iodophilic polysaccharide in two cariogenic strains of Streptococcus mutans by cytochemical and chemical methods. Infection and Immunity 10, 597-604.

Dubois, M., Gilles, K. A., Hamilton, J. K., Rebers, P. A. \& SMith, F. (1956). Colorimetric method for determination of sugars and related substances. Analytical Chemistry 28, 350-356.

Gibbons, R. J. \& Kapsimalis, B. (1963). Synthesis of intracellular iodophilic polysaccharide by Streptococcus mitis. Archives of Oral Biology 8, 319-329.

Gibbons, R. J. \& SocransKy, S. S. (1962). Intracellular polysaccharides stored by organisms in dental plaques in relation to dental caries and microbe ecology of the oral cavity. Archives of Oral Biology 7, 73-80.

Holdeman, L. V. \& Moore, W. E. C. (1972). Anaerobe Laboratory Manual. Blacksburg, Virginia, U.S.A.: Virginia Polytechnic Institute and State University.

Houte, J. VAN (1967). Iodophilic polysaccharide in bacteria from the dental plaque. Thesis, Utrecht, The Netherlands.

Huggett, A. St. G. \& Nixon, D. A. (1957). Use of glucose oxidase, peroxidase and $o$-dianisidine in determination of blood and urinary glucose. Lancet ii, 368-370.

Hughes, D. E., WimpenNy, J. W. T. \& Lloyd, D. (1971). The disintegration of micro-organisms. Methods in Microbiology 5B, 1-54.

Lato, M., Brunelli, B., Ciuffini, G. \& Mezetti, T. (1969). Thin layer chromatography of carbo- 
hydrates on silicagel impregnated with sodium acetate, monosodium phosphate and disodium phosphate. Journal of Chromatography 39, 407417.

Lindner, J. G. E. M. \& Marcelis, J. H. (1978). Quantitative gas chromatography of Bacteroides species under different growth conditions. Antonie van Leeuwenhoek 44, 1-14.

Macy, J., Probst, I. \& Gottschalk, G. (1975). Evidence of cytochrome involvement in fumarate reduction and adenosine- 5 -triphosphate synthesis by Bacteroides fragilis grown in the presence of hemin. Journal of Bacteriology 123, 436-442.
Schmid, F. H. (1961). Die enzymatische Bestimmung von Glucose und Fructose nebeneinander. Klinische Wochenschrift 39, 1244-1247.

Stouthamer, A. H. (1969). Determination and significance of molar growth yields. Methods in Microbiology 1, 629-663.

ThIéry, J. P. (1967). Mise en évidence des polysaccharides sur coupes fines en microscopie électronique. Journal de Microscopie 6, 987-1018. VIES, J. VAN DE (1954). Two methods for the determination of glycogen in liver. Biochemical Journal $57,410-416$. 